\title{
The TENPLA Project: Communicating Astronomy with the Public in Japan
}

\author{
Naohiro Takanashi ${ }^{1}$ and Masaaki Hiramatsu ${ }^{2}$ \\ ${ }^{1}$ National Astronomical Observatory of Japan, \\ Mitaka 181-8588, Japan \\ email: naohiro.takanashi@nao.ac.jp \\ ${ }^{2}$ Institute of Astronomy and Astrophysics, Academia Sinica, \\ P.O. Box 23-141, Taipei 10617, Taiwan, R.O.C. \\ email: hiramatsu@asiaa.sinica.edu.tw
}

\begin{abstract}
The TENPLA project (pronounced as "ten-pla", like a famous Japanese food "Tempura") is designed to communicate Astronomy with the public in Japan. We have been working to suggest various ways to enjoy astronomy. We have organised star gazing parties, science cafés, and lectures. We have made many goodies which make people interested in astronomy (e.g. "Astronomical Toilet Paper"). We have also provided opportunities to communicate with each other for people who have interests in such activities. In this paper we present a broad overview of the TENPLA project.
\end{abstract}

Keywords. science communication, outreach, Japan

\section{Introduction}

Astronomical Toilet Paper (ATP) $\dagger$ is a toilet paper printed with a story about life of a star (Fig.1). People can literally touch and enjoy the Universe at a bathroom. Some 40,000 rolls have been sold in Japan.

The ATP was produced by the TENPLA Project in 2005 (cf Hiramatsu et al. 2006; Kamegai et al. 2006). The TENPLA Project is the largest network among people who want to enjoy Astronomy with the others in Japan. There are over 250 members with a variety of specialties, from students to mothers. The project is dependent from any institutions or organisations. The purpose of the TENPLA Project is enjoying Astronomy with the public. We welcome that our activities result in education but education is not the purpose of our activities. Enjoying astronomy with the public is the only purpose of our activities.

The TENPLA Project was started in 2003. M. Hiramatsu and N. Takanashi organised graduate students who are interested in communicating astronomy with the public. At the start of the project, we collaborate with science museums and/or planetariums because we thought we can meet the public at the places. We enjoyed the activities at the places, however, soon we noticed that most of the public does not come to the places since they do not have a special interest with astronomy or science.

In order to communicate with the public who do not come to the places, we went out from the science museums and/or planetariums. We held star gazing parties, lectures, and science cafés in the center of the town. Through the events, we could communicate with the public who does not come to the places.

$\dagger$ ww. tenpla.net/atp/indexE.html 




Figure 1. Astronomical Toilet Paper. The story of the life of a star is printed on the paper.

Also we started to make astronomical goodies. The public can get those goodies at shops in the city unless they do come to the science museums and/or planetariums. Through the charming goodies, we can communicate with the public who has interested with such goodies.

Then, we noticed that there are people who have some barriers to enjoy astronomy. For example, hospitalised patients can not join a star gazing party even if we hold the party in the town because they can not go out from the hospital. Mothers with a baby also have difficulty in joining a lecture because they worry about the baby may be noisy for the other participants. There are less chances to enjoy Astronomy for lower grades students because usually educators believe they can not understand the Universe. We have found such people who have some barriers and suggested appropriate way to enjoy astronomy for them (Fig.2).

As a result, nowadays we communicate Astronomy with all of those people through various ways. In the next section, we present some examples of our activities.

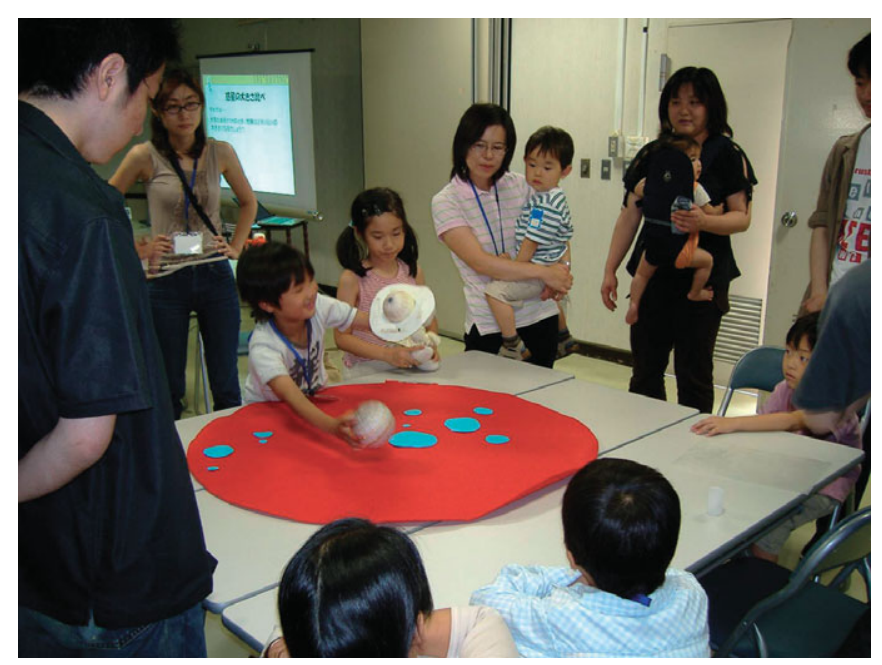

Figure 2. Lecture for mothers with infants. 


\section{Activities}

There are mainly three types of activities : (1) communication with the members, (2) communication with the public, and (3) communication with the other groups.

Communication with the members is a very important activity. The members join to the project have various specialties. Students are the largest group of the members which consist of not only the students who major in astronomy but also the students who major in education, communication, art etc. Educators are also large group, on the other hand, there are the members who have a unique specialty. For example, amateur astronomers, designers, officers working at government, and mothers. They also want to enjoy communicating astronomy with others. Communication among these members inspire a unique idea of enjoying astronomy with the public. We usually communicate each other through a mailing list and off-line meetings.

Communication with the public is the main activity of the project. We communicate with the public through the events such as star gazing parties, lectures, science cafes. Astronomical goodies such as the ATP also help us to communicate astronomy with the public. Those activities prefer to be unique and challenging. We show some examples below.

Star Gazing Party. We have held numbers of star gazing parties. In Japan, most of people who live in large city like Tokyo believe that they can not watch stars because night sky is bright by light pollution. For the people, we encourage to watch stars through the star gazing parties. In order to motivate people to join the parties, we choose an attractive location for the parties. For example, we held star gazing party at local airport (Fig.3). We watched shooting stars lying on the runway!

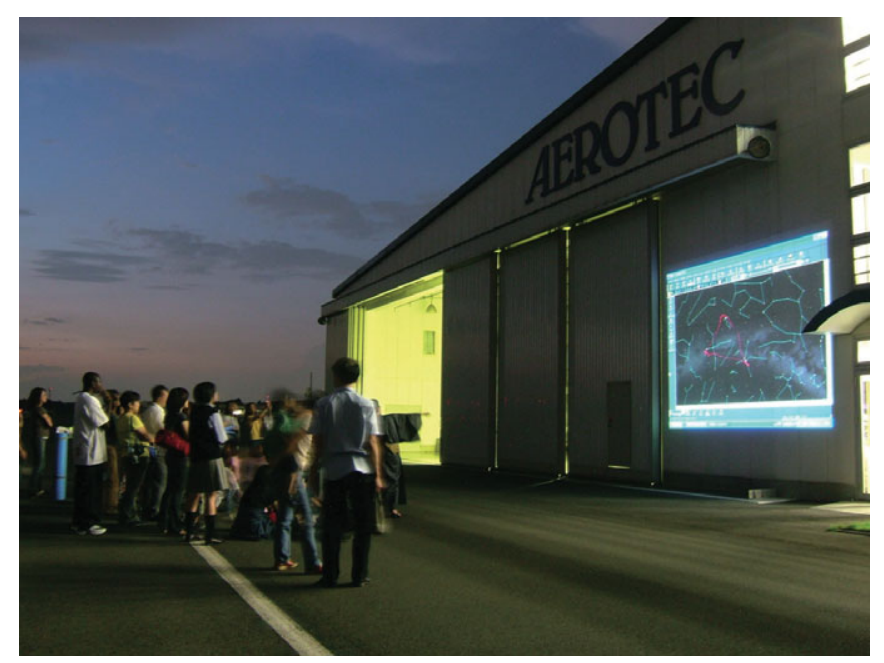

Figure 3. Star gazing party at a local airport.

Science Café. Café Scientifique, originally derived from Café Philosophique, was born in UK (c.f. Dallas 2006). It was introduced in Japan a few years ago, and now it has become very popular. We have also carried out various science cafés. The main purpose of the cafes is to provide a chance to talk about astronomy with researchers, however, usually Japanese people hesitate to talk with them since they are very shy. In order to facilitate the discussion, we put many young graduate students on the cafe as a facilitator.

Lectures. Not only lectures for the adults, we hold a club activity at the local school once a month. About 30 children and their parent join the activity. We talk about the 
latest news of astronomy at first, then we watch stars from rooftop of the school building. In Japan, it is difficult to find such club activities for school kids. We provide a chance to those kids to touch Astronomy. When the Pluto was in the news, one of the TENPLA members who attend the IAU conference talked about it. We can deliver latest news with easy explanations

Events for non-Japanese citizens. Recently, there are many foreign citizens in Japan. However, there are less chances which non-Japanese people can enjoy enough. So we held an event with multilingual guide. We guided campus of National Astronomical Observatory of Japan in English, Korean and Japanese. In the near future, we plan an event in German and Thai.

Communication with the other groups is also an important activity for us. We attended many meetings related to communicating astronomy with the public in order to explore a new possibility of a way. The theme of the meetings is not only astronomy but also science communication, art, child care, etc. We outreach our way of thinking through such meetings.

\section{Summary}

As we have shown here, the TENPLA project has been working on many kinds of activities in Japan. Through the activities, we have provided the public with the chance to enjoy astronomy. These activities are designed to attract people even if they don't have special interest in astronomy. Since we want to give a chance for all the public equally, we focus on people who have a barrier to join the activities.

\section{References}

Dallas, D. 2006, Cell, 126, 227

Hiramatsu, M., Takanashi, N., Kamegai, K., \& Tsukada, K. 2006, Innovation in Teaching/Learning Astronomy Methods, 26th meeting of the IAU, Special Session 2, 95

Kamegai, K., Hiramatsu, M., Takanashi, N., \& Tsukada, K. 2006, Innovation in Teaching/Learning Astronomy Methods, 26th meeting of the IAU, Special Session 2, 98 